\title{
Discussion on the Reform of Integrated Course Design of Measurement and Control Technology and Instrumentation
}

\author{
Dong Guimei (Corresponding Author) \\ College of Engineering and Technology \\ Tianjin Agricultural University \\ Tianjin, China \\ 32568403@qq.com \\ Yang Renjie \\ College of Engineering and Technology \\ Tianjin Agricultural University \\ Tianjin, China \\ rjyang1978@163.com \\ Yang Yanrong \\ College of Engineering and Technology \\ Tianjin Agricultural University \\ Tianjin, China \\ 1605471320@qq.com
}

\author{
Wei Yong \\ College of Engineering and Technology \\ Tianjin Agricultural University \\ Tianjin, China \\ weiytj@tjau.edu.cn \\ Yu Yaping \\ College of Engineering and Technology \\ Tianjin Agricultural University \\ Tianjin, China \\ yaping261@163.com \\ Liu Yuan \\ College of Engineering and Technology \\ Tianjin Agricultural University \\ Tianjin, China \\ 1417325528@qq.com
}

\begin{abstract}
Aiming at the disadvantages of the integrated course design of traditional measurement and control technology and instrumentation, such as the lack of comprehensiveness, systematization and integrity, the absence of innovation in teaching, the lack of a uniform quantitative criteria for the evaluation system, etc., the more in-depth discussions are made on the reform of integrated course design. Based on the project platform, the comprehensive and systematic course design subjects are proposed; for different abilities of students, multilevel multi-directional course design subjects are put forward to encourage students to create their own projects; a sound evaluation system is established by setting the difficulty coefficient for students to create a new space for improvement. Through the reform program the integrated course design made useful attempts, and achieved good results.
\end{abstract}

Keywords-Reform; Integrated course design; Measurement and control technology and instrumentation; Evaluation

\section{INTRODUCTION}

Measurement and control technology and instrumentation is one of the traditional specialty which has the most measurement characteristics in college of engineering and technology. It is a major of the interdisciplinary fusion, combining light, machine, electricity, calculation with one integrated application instrument, which is to cultivate the comprehensive engineering technology talents with integrated technology of measurement and control fields and

1. Research Project of Quality of Teaching and Reform in Education of Undergraduate in Tianjin College (171006101C).

2. Tianjin Science and Technology Development Fund of Higher School (20140621) comprehensive instrument design and application ability [1].

The integrated course design of the measurement and control technology and instrumentation is a large-scale practical training in practice teaching, aiming at training the students' basic abilities of system analysis, design, development and research. Through the integrated teaching practice of course design, students can consolidate the basic theory and professional knowledge they learned; understand the design steps of the measurement and control system and the development process of hardware and software; master the methods of data collection, collation and analysis of related topics, program design and comparison, to improve students' ability to analyze problems and solve problems, which make necessary preparations for the follow-up graduation project and engineering practice.

However, due to many reasons, there are various disadvantages in the traditional integrated course design pattern. First of all, the subject is not comprehensive and lacks systematicness and integrity. The original course design of measurement and control technology and instrumentation reflects the training requirements of the measurement and control major on the design ability of mechanical structure, measurement and control circuit and SCM courses, but they are relatively independent of each other in design content and cannot combine the light, machine and electricity organically together, as well as lack of systematicness and integrity, which has a great distance with actual practice. Second, the subject is 
single and cannot be taught according to aptitude. The past issues of the design with a unified subject, unified requirements, does not adapt for students with different abilities, so that capable students cannot be further improved, while students with low ability feel difficult to control, which limit the development of potential of students and cultivation of practical ability. Furthermore, the evaluation system is flawed, and the thinking, abilities, and methods in the design work that are usually done are not taken into account because there are no unified quantitative criteria. Acceptance scores are mostly evaluated in means of design information submitted by students, which is likely to result in deviation from the actual situation, being unfair. And the past evaluation criteria are relatively simple, resulting in that the students trained have poor practical ability, lack of innovation and enthusiasm [2]. Therefore, we must reform the shortcomings of the original design patterns and actively explore new, efficient and practical integrated course design patterns. In this paper, aiming at the shortcomings of the integrated course design of measurement and control of technology and instrumentation, based on the goal of integrated course design, the corresponding reform proposals are put forward and discussed.

\section{PROSPECTIVE EFFECT OF INTEGRATED COURSE DESIGN}

\section{A. Planning of Integrated Course Design}

\section{1) Purpose of integrated course design}

The teaching purposes of integrated course design in measurement and control technology and instrumentation are as follows: a. to enable students to understand and grasp the basic control of the whole process of measuring and controlling instrument design and all aspects related; b. to train students of design ideas with connection between theory and practice, training students to have the ability to solve specific design problems by integrated use of theoretical knowledge of measurement and control technology and instrumentation and modern design tools; c. to enable students to consolidate and systematically master the basic theoretical knowledge of measurement and control technology and instrumentation and a variety of modern design tools; d. to develop ability to solve engineering problems by an integrated application of light, electricity, calculation and other knowledge; e. to enable students to recognize the importance of collaboration with people and collaboration skills through completing a design task with a team of people; f. to enable students to master the writing method of design report and basic skills, cultivating the quality of engineers [3-4].

\section{2) Process of integrated course design}

After we get course design task, the course design includes several parts: design preparation, design scheme, design implementation and test, precision analysis, writing design report and grade evaluation, which are as shown in Fig.1, covering all the teaching content and all teaching links [5]. The problems to be solved in the overall design process include the design task analysis and concept of innovation, the consideration of some design principles of measurement and control instruments, the discussion of some design principles of measurement and control instruments, the selection of working principle of measurement and control instruments and system design, the main control systems structural parameters and technical indicators to be determined, and the structure design of measurement and control equipment. To complete the task, first of all design preparation is made according to the task of the course design, including analysis of subjects, data collection, and comprehensive research. Followed by project demonstration, it is to determine the design scheme to meet the project requirements of the mechanical structure and electrical hardware and software system. And then hardware and software are made implementation and commissioning to find problems and solve problems. Again accuracy analysis is carried out to improve the system. Finally reply and score evaluations are done.

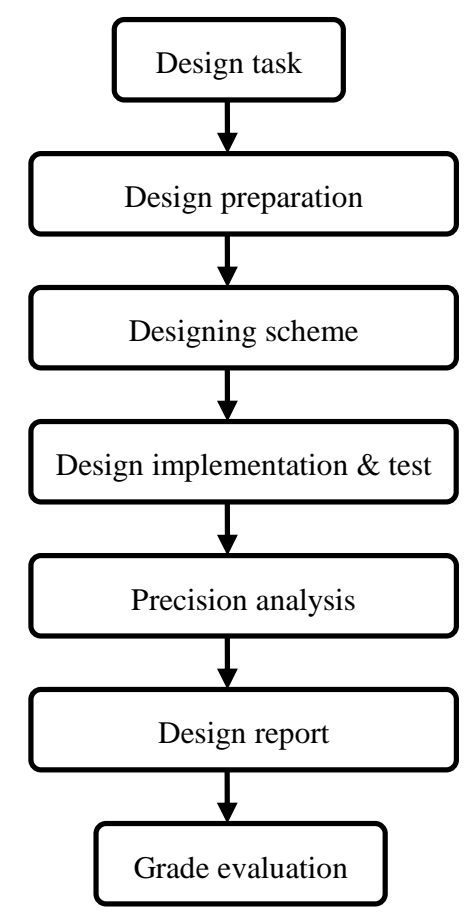

Fig. 1 The whole process of integrated course design

\section{3) Principle of subject selection}

A typical measurement and control instrumentation system, including precision mechanical systems, optoelectronic systems and software systems and other subsystems, in order to allow students to establish a complete concept, whose design work should be involved in all aspects above. Accuracy analysis and synthesis belong to the category of instrument error synthesis. Through the accuracy of the instrument we can verify whether the accuracy of the design is reasonable. Design specification is the summary and promotion of the entire design process of the project, and is also an important document literature of engineering exchange. By guiding students to write professional integrated course design report, students are developed the ability to write engineering and technical documents. Therefore, the subject of integrated professional course design must comply with the following principles: a. preferably including precision mechanical systems, optoelectronic systems and software systems and other subsystems; b. has a variety of solutions for program 
analysis and comparison; c. the solution process can reflect innovative ideas, through the teacher's explanation for students to understand the important role of the creative thinking in the measurement and control instrumentation [6].

\section{B. Objectives of Integrated Course Design}

Based on the above factors, the following points are proposed for integrated course design of measurement and control technology and instrumentation:

(1) Develop a comprehensive, systematic and industry-level course design subjects based on the project platform. In view of the overall social needs and the needs of employers, it is very important to cultivate compound talents with broad knowledge, strong comprehensive ability, practical focus, strong adaptability and self-learning capability. Integrated course design is a very important practical link for cultivating and improving students' practical abilities and laying a solid foundation for their adaptation in the future. The subject of the integrated course design should be of a certain engineering nature and forward-looking. Students should as far as possible get practical engineering training, improve practical ability, deepen the understanding of professional knowledge.

(2) Put forward a multi-level multi-directional course design subject to encourage students to create their own projects for different abilities of students. The subject should be able to fully mobilize the imagination of students, establish awareness of engineering, improve innovative thinking, and develop innovative ability. The completion of a project, involving all aspects of knowledge, require more students to cooperate successfully, and is conducive to cultivating a high sense of responsibility and team spirit.

(3) Establish and improve the evaluation system, set the difficulty coefficient, to create space for improvement for students. Before the integrated course design, the difficulty of the subject should be evaluated comprehensively. Some functions should be improved under the premise of completing the basic function. In order to make a more comprehensive and realistic assessment of the student's course design, the examination should be carried out in strict accordance with the project acceptance. Assessment include: the usual performance, function implementation, accuracy reached, design report, oral examination, etc., and each of the scores for quantification, which are synthesized as the students' final course design grade.

\section{Requirements of Integrated Course Design}

For these goals, we need to strengthen the construction, the specific implementation of the contents need to focus on the following points:

(1) In accordance with market demand for research projects, to collect light, machine, electricity and multi-disciplinary integration of the project as the subject, with the project development as the main line, the relevant theoretical knowledge are integrated into the development of all aspects of the project to give students fully hands-on platform. According to the requirements of engineering practice, advance at every level, cultivate students' practical ability of multi-field integration;
(2) The project is divided into different levels of modules available to students, according to their interests and abilities, which the appropriate subject is chosen for design and development. Promote teamwork development and teamwork awareness among student sub-groups. At the same time, encourage students to self-title, pioneering and innovative.

(3) Improve the course design evaluation system, with the ability to evaluate oriented, highlighting the process, using the method of increasing the degree of difficulty in the development of multi-level course design evaluation criteria. Encourage students to achieve the basic pass points, to improve the difficulty of developing potential and continuously improve their own practical ability.

\section{REFORM POINTS OF INTEGRATED COURSE DESIGN}

Based on the experience of many years of integrated course design, project team members conducted a more in-depth discussion on the reform of integrated course design and proposed a new program of reform:

(1) The choice of the subject is the key to the implementation of the integrated course design, and the subject should be done with engineering, forward-looking and comprehensive. This requires, prior to the integrated course design, more market research should be conducted to understand the needs of enterprises. It also can be combined with the vertical and horizontal issues of the teachers, taking full into account that the teaching content of the professional course design and interface requirements of professional training is a systems engineering. From the perspective of course design teaching hours, design requirements, design features, the subject with forward-looking, engineering, moderate difficulty are chosen integrated light, machine, electricity, count at an organic whole. Subjects are in strict accordance with the project implementation, and fully mobilize the imagination of students, establish a sense of engineering, improve innovative thinking, develop system design capabilities; stimulate student interest, improve learning initiative, so that the combination of the boring optical, mechanical, electrical, computer-based design become lively, fun and rewarding. During the design period, teachers and students solve the problems of course design through interdisciplinary discussion, research, exchange and other interactive activities. All course design has related theoretical courses as a support, and effectively train students to analyze problems, solve problems and the ability to process information.

(2) To explore the application of diversified and multi-level projects in course design, give students the initiative to choose subjects, and to teach students according to their abilities according to different abilities. The completion of a project involves all aspects of knowledge, so we promote the group division of labor and collaboration, which is conducive to cultivate a high degree of responsibility and teamwork spirit. At the same time, set the difficulty factor to encourage competent students on the premise of completion of the pass points to go on further research and development of new functions on the project platform, which gives students full display of talent and pioneering and innovative space. In 
addition, to encourage students to put forward their own ideas of the project, and the students can implement the project in advance or synchronously after the workload and difficulty are identified by the course group teachers, which greatly stimulates students' enthusiasm for independent innovation design, helps teachers to guide students from part to the whole, from easy to difficult, step by step to complete a system design. The students do more than just a project, but development ideas based on the project's system, which improve the overall design ability of students.

(3) In the process of course design reform, we emphasize the system of course design for process evaluation, and set up the evaluation system of graduation system for different degree of difficulty items. The evaluation of course design is to determine students' achievements in terms of ordinary performance, function implementation of physical production, precision attained, design report, and oral examination, whose distribution proportion is shown as Fig.2. From the workload the students usually involved in the design, the degree of final completion and degree of difficulty, the quality of the design report and the defense speech and questions answering on the spot and other aspects, the design ability and level of students are evaluated synthetically. For students who choose to have a high degree of difficulty, innovative mindset, and innovative design, they will be given a bonus by making a variety of projects or developing innovative elements in their projects so as to promote the evaluation of individual abilities. Taking the work done by students and their corresponding abilities as evaluation can also effectively restrain students from plagiarizing each other and fully mobilize the students' creativity and initiative in designing, which is conducive to improving the quality of integrated course design and students' ability to apply knowledge to practice.

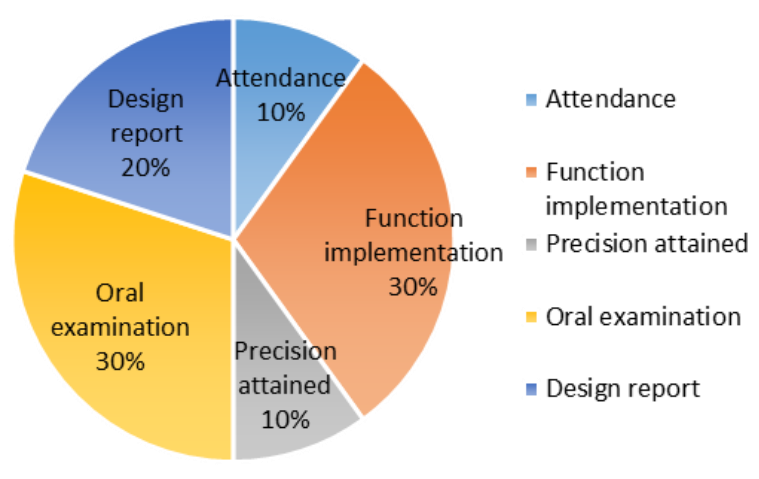

Fig. 2 Proportion of assessment indicators of grade

\section{CONCLUSIONS}

For the characteristics of the major of measurement and control technology and instrumentation and the defects of the traditional integrated course design, this paper reforms the teaching methods of integrated course design and proposes a comprehensive and systematic subjects based on the platform of engineering project. The multi-level and multi-directional course design subjects for students with different abilities are put forward to encourage students to create their own projects. A quantized evaluation system is established, which creates new space to improve for students. This reform program pays great attention to cultivating students' initiative and consciousness in learning, and promotes individualized development of students and improvement of overall quality. The practice showed that this reform program has stimulated students' interest in learning, improved the initiative and consciousness of learning, and cultivated students' comprehensive, practical and innovative ability and has achieved good results.

\section{ACKNOWLEDGMENT}

This work was financially supported by the Research Project of Quality of Teaching and Reform in Education of Undergraduate in Tianjin College (171006101C), and Tianjin Science and Technology Development Fund of Higher School (20140621).

\section{REFERENCES}

[1] Gu Peihua. From CDIO to EIP-CDIO: A Probe into the Mode of Talent Cultivation in Shantou University[J]. Research in Higher Education of Engineering, 2008(1): 12-19. (In Chinese)

[2] Zheng Jiamao. Constructing Open Innovation Experimental Teaching System[J]. China Higher Education, 2009(5): 39-41. (In Chinese)

[3] Zhuang Zhijun. Research and Practice on Cultivating Measures of Students' Practice and Innovation Ability in Common Engineering Colleges[J]. Journal of Jilin Institute of Chemical Technology, 2012, 29(2): 38-40. (In Chinese)

[4] Wan Sizhi. Exploration of the Implementation Way of College Students Innovation Experimental Plan[J]. China Higher Education, 2010(8): 4243. (In Chinese)

[5] Zhang Xuehong. Building Practice Teaching Platform to Improve Students' Innovative Capacity[J]. China Higher Education, 2012(6): 25-27. (In Chinese)

[6] Wang Daihua. Practice on Guiding the Specialty Synthetical Course Project in the Major of Measurement \& Control Technology and Instruments[J]. Research in Higher Education of Engineering, 2007(3): 125-128. (In Chinese) 